\title{
Rhythms, flows and structures of cross-boundary schooling: state power and educational mobilities between Shenzhen and Hong Kong
}

\begin{abstract}
This paper explores the phenomenon of cross-boundary schooling (CBS), where more than 30,000 children undertake a daily, check-point-crossing commute to school and back again, over the Hong Kong - Shenzhen border. It elaborates on the notion of 'state assemblage' to consider how the power of the state (in this case, both the PRC and Hong Kong authorities) manifests in CBS and, in particular, how the state attempts to exert control over children's and parents' bodies. This view of CBS contrasts with a sense of 'agency' that prevails around discussions of educational mobilities, and we explore this tension here. The paper focuses on two related aspects of CBS - materiality, and the role of habit and rhythm, in directing, guiding and cajoling children to conform to an extremely rigid and regimented daily routine. We found that the material structures that make up the border are crucial in enabling CBS to 'function' and that notions of rhythm and habit are very useful for understanding how the 'flow' of educational mobilities is achieved. At the same time, we considered instances where flow was disrupted, rhythms were changed and individuals somehow resisted the material constraints of the border.
\end{abstract}




\section{Introduction}

'My son goes to school here in Shenzhen. His school is just downstairs. My daughter goes to Hong Kong for schooling. It is kind of troublesome'. (Fieldwork interview with ZY, mother of CBS child, 2018).

'The diffuse working of power seeks rhythmic conformity...' (Edensor and Holloway, 2008, p. 501).

During the week, Monday to Friday, tens of thousands of children, attending kindergarten through to high school, cross the border between Shenzhen (in the People's Republic of China) and Hong Kong (Special Administrative Region), at one of nine busy ports. They cross in the morning, to attend school in Hong Kong, and back again in the afternoon or early evening, to return home to Mainland China. As ZY wryly indicates in the quotation above, this trip is quite 'troublesome'. Each crossing involves border checks by government officials and sometimes several hours (up to 4 for some children) of travelling in total. Crossboundary schooling (CBS), as it has become known, is not unique to the Shenzhen-Hong Kong region, and can be observed at state and internal borders, globally. Shenzhen-Hong Kong, however, is notable for the sheer number of CBS children crossing daily; according to statistics from the Shenzhen General Station of Exit and Entry Frontier Inspection, more than 30,000 students aged 3 to 13 in Shenzhen travelled across the boundary to go to schools in Hong Kong in 2017. Notable also is the extent to which the border and its infrastructure have been adapted, materially, to accommodate the recent and dramatic rise in numbers, from only a few hundred children just fifteen years ago. During our fieldwork at the border, over the 
space of a morning we observed a cascade of hundreds of uniformed children ${ }^{1}$ moving together, synchronised, in lines, in a display of orderliness. There is a conceptual tension, within CBS, that we wish to explore in this paper. On the one hand, CBS would seem to represent the quintessence of 'educational mobilities', evoking a flow of people across a border seeking opportunities attached to education (e.g. Ong, 1999). Educational mobilities, as discussed in the academic literature, indicate the agency of families making positive and active choices around children's education, which increasingly includes the crossing of borders (Waters, 2017). On the other hand, CBS represents the control of the state over Mainland Chinese families. The securitised border, with its check-points, barriers, lanes, funnels, secret rooms, security camera and police, signifies the epitome of state power. It is where the state is most clearly and obviously manifest in the daily lives of border-crossers. As a system and procedure, the border also seems to work: functioning to control the movement of people but also enabling ostensible 'flow' and 'frictionless' movement/mobilities. It is underpinned by a hard material infrastructure - what could be described in terms of a 'state assemblage' (Dittmer, 2018). In this paper, therefore, we counterpose the power of the state to control the mobility (and lives) of CBS families, centring on the border, with the purported 'agency' of Mainland Chinese households 'choosing' to put their child in school in Hong Kong.

We explore two particular aspects of cross-boundary schooling between Shenzhen and Hong Kong. First, we consider border materialities - props, artefacts, structures, barriers and technology - and the ways that they both facilitate and impede the flow of people. Second, we focus on the role that habit and rhythm (with a material basis) play in creating flow and

\footnotetext{
${ }^{1}$ Unlike in parts of Europe, uniform is commonly worn by school children in Hong Kong.
} 
counter-flows in educational mobilities. Whilst habit and rhythm support - and reproduce twice-daily - state power, we also uncover places and moments of relative immobility and disruption to rhythmic conformity (stopping, pausing, waiting, sitting, sleeping) amidst an ostensible stream of bodies and continuous, orchestrated movement, asking how these potentially challenge state power (albeit in modest and understated ways), redefining the space of the state at the border. Control is practised and resisted in different ways and times by different actors, and we try to identify some of these in this paper.

In addition, we wish to place cross-boundary schooling in the context of recent scholarship on 'educational mobilities', which has included (but is not limited to) work on 'international students', migrant students and the internationalisation of education (Brooks and Waters, 2011; Finn and Holton, 2019). Within this work, children's mobilities are still relatively neglected. So, too, is the way in which educational mobilities intersect with state power. Globally, many children cross borders or boundaries in order to access educational opportunities (see Waters 2006, 2015), although only a relatively small number do so in a way that necessitates quotidian border crossings, wherein the impact and meaning of the border (and the state) on daily life is even more profound. There is a dearth of research on daily boundary crossing for schooling (although see Chiu and Choi, 2018; Chee, 2017). Furthermore, the literature on international student mobilities has generally had little to say about the materialities of those mobilities (how they involve sleeping, eating, waiting, busing and learning according to different rhythms and timings) (Brooks and Waters, 2017). This paper goes some small way towards enriching the literature on educational mobilities by addressing these omissions. 


\section{Research context}

The border between Hong Kong and Mainland China was, historically, an open one. As Newendorp (2008) notes in her ethnography of families across this border region, before the establishment of the People's Republic of China (PRC) in 1949, there were no restrictions on the movement of Mainland individuals over the Hong Kong/Mainland border: 'since many individuals routinely crossed the border to work, visit relatives, or take care of marketing needs' (p. 42). Over the next thirty years, immigration policy became far more restrictive and free movement over the border ceased. In 1997, with the handover of the territory from the United Kingdom to the PRC, Hong Kong and the Mainland became part of 'one country' (two systems). Nevertheless, the border continued to be experienced as highly restrictive, especially for Mainland Chinese residents: 'the border serves as a concrete reminder of both the actual and perceived differences that exist between cosmopolitan Hong Kong people (Cantonese: Heunggongyahn) and their "backward" mainland Chinese "cousins"

(Newendorp, 2008, p. 14). Despite the one country rhetoric, Hong Kong permanent residents and PRC citizens hold different passports, allowing differential mobility and access to countries worldwide.

Nearly all of the children undertaking CBS were born in Hong Kong and have Hong Kong residency, despite the fact that at least one parent (and often a sibling) is a Mainland Chinese citizen and the family resides in the PRC. There are many reasons why women chose to give birth to this child in Hong Kong, but key was an attempt to 'get around' China's one-child policy $^{2}$. At that time (and until 2016), parents wishing to have more than one child within the PRC faced several (limited) options: to give birth on the Mainland, register the birth, and pay

\footnotetext{
${ }^{2}$ China's one child policy was announced in 1978 (limiting married couples to only one child by law) and reflected an emphasis shift in state discourse from population 'quantity' to 'quality' (Anagnost, 1995).
} 
a very hefty financial 'fine'; to give birth on the Mainland and not register the birth, thus avoiding the fine but, consequently, ensuring that one child will grow up with no legal status in the PRC (or elsewhere), thereby denying them access to healthcare, public schooling, ability to work as adults, and so on. A third option, and the one taken by the participants in our research, was to give birth to a second child in Hong Kong. This was, and is, not without its associated problems - the second child is a legal Hong Kong resident but has no official status within the PRC. His/her parent(s) and sibling(s) have PRC citizenship but no legal status in Hong Kong. These became known as 'double-not' families, wherein: 'neither parent has the right to reside or work in Hong Kong and their cross-border mobility is very limited; their Hong Kong-born children have no household registration (hukou) in mainland China and are therefore not entitled to social security, state subsidised schools, or medical services there.' (Chan and Ngan, 2018, p. 147). A smaller number of children in our study had one parent with Hong Kong residency status - these are known in local parlance as 'single-not' families.

Children born in Hong Kong (but living in the PRC) had, for many years, no choice but to attend school in Hong Kong as they were legally unable to attain a place at a public school on the Mainland. Even though this situation has changed over the past few years (since 2017, the Chinese government has allowed children in some 'double-not' families to attend a limited number of public schools in Shenzhen) cross-boundary schooling continues unabated. There are complex reasons for this continuation, but they include a preference for Hong Kong's education system, linked to ideas around educational 'choice' - some seeing it as a stepping stone to 'future mobility' including international study. Indeed, some women chose to give birth in Hong Kong with their child's future schooling as the primary reason given. Our 
interviews with mothers of CBS children gave lots of reasons why the schooling system in Hong Kong was preferred, as these couple of examples suggest:

SY: I could write a book about it. Advantages: first, it is cheap in HK. I spent around 2000 HKD one semester [£198]. In Shenzhen, it normally takes 3000 RMB per month [£350]. Second, in HK, I think the teachers won’t beat my son. In Shenzhen, I worry that my kid might be beaten (by teachers). Third, HK has many English-native speakers, and it is good for him to learn English.

ZYY: I think English is important, I know the importance of English. My English is not good, and I hope my son will learn it well, but I am unable to give him any help, because I am not good at it. At the beginning, I find some tutoring centers in Shenzhen. But my husband said, it was Chinglish, taught by Chinese. I don't want my son to learn this. If we find some international schools in Shenzhen, it is very expensive...HK is an international city. English is semi-native language for them. It is better in HK to learn English.

The decision of families to give birth to a second child in Hong Kong is directly related to an important legal ruling about the residency status. Prior to this ruling in 2001, children born in Hong Kong to Mainland resident parents had no status there (in Hong Kong). However: 'In 2001, the Court of Final Appeal ruled that all children born in Hong Kong were entitled to permanent Hong Kong residency, irrespective of their parents' residency status' (Chan and Ngan, 2018, p. 147). According to Chan and Ngan (2018), this ruling 'prompted tens of thousands of mainland women to give birth in Hong Kong in order to acquire residency for 
their offspring' (p. 148). Babies born in Hong Kong to Mainland parents rose at a staggering rate, from 620 in 2001 to more than 35,000 in 2011 (38\% of total births in Hong Kong).

Another relevant policy change occurred after 2003, when Hong Kong attempted to 'liberalise' its border for some Mainland residents (linked to the SARS outbreak ${ }^{3}$ and the need to provide a 'quick fix' for the Hong Kong economy). It introduced the Individual Visit Scheme (IVS) to boost tourism, allowing individuals from the Mainland to enter for up to seven days (previously only group or business visits were allowed). The change in the law resulted in a 3348\% rise in Mainland tourists to Hong Kong in a decade (Chee, 2017). In short, the IVS made it possible for women to travel to Hong Kong as tourists whilst pregnant to give birth ${ }^{4}$ (this policy has subsequently been reversed), before returning to the Mainland to live. These children had an automatic right to Hong Kong residency and all the 'privileges' that affords.

Fast forward to when the time came for these children to enter kindergarten/pre-school in Hong Kong: Figure 1 describes in detail the clearance procedures and transportation arrangements for CBS. This 'state assemblage' ensures that authorities are 'in control' of cross-boundary schooling. And yet, there is still very little understanding of how CBS is enacted (by people, daily) in relation to these procedures and assemblages; how (and if) the state controls the tens of thousands of people that engage in CBS; how it attempts to exert

\footnotetext{
${ }^{3}$ Between the end of 2002 and early 2003 there was an outbreak of severe acute respiratory syndrome (SARS) resulting in hundreds of deaths in Hong Kong and southern China.

${ }^{4}$ In 2014, Hong Kong made it illegal for public hospitals to accept maternity bookings from Mainland Chinese women. Although cross-border births have continued illegally, it is widely reported in the press that numbers have decreased substantially since this policy change and that pregnant woman are frequently arrested at the border. It should also be noted that 'birth tourism' (as it is called) by Mainland mothers can be seen in Canada, the US, Australia and New Zealand too.
} 
control over children's and parents' (mainly mothers') bodies, and how these attempts might be subverted or resisted by families and children. Through our data, the significance of rhythm and ingrained habit (through repetition) was evident and, we argue here, is intimately linked to governmentality in the way that other authors have described (e.g. Dewsbury and Bissell, 2015). Interestingly, however, CBS has developed precisely out of the inability of the state to control women's pregnant bodies and children's births (Waters and Leung, 2018). ${ }^{5}$ As we have indicated and explore below, CBS is in part a function of families' attempts to by-pass the one-child policy that was enforced in China between 1979 and 2015.

\section{Intellectual context}

This section begins with a discussion of the recent, burgeoning work within the social sciences that centres on educational mobilities and/or education-related forms of migration. We then move on to consider scholarship that has concerned both materialities and the role and function of ports as spaces that enable/restrict mobilities of different kinds (see Adey, 2008). We focus, specifically, on the notion of assemblages, not least because of the politics that work on assemblages evokes (Dittmer, 2018; Barry, 2013). The port is an inherently political space, and the way that the state(s) attempts to control movement at the border is a decisive, politically inflected act. Finally, we consider recent scholarship on rhythms, habits and movement, as a potentially productive way of theorising state control, 'educational flows' and 'counter-flows' associated with moving children over the border.

\section{Educational mobilities}

\footnotetext{
${ }^{5}$ Space precludes us developing this idea here, but it is something we are pursuing in other publications.
} 
Interest in education and mobilities has grown significantly over the past decade or so, where previously only a small number of researchers worked in this area (Brooks and Waters, 2011; Waters and Brooks, forthcoming). Now we see substantive, insightful research on a range of related topics, including: mobility for higher education (Brooks, 2018; Holton and Finn, 2018; Finn, 2017; Patiniotis and Holdsworth, 2005), international student mobilities (Beech, 2018; Findlay et al., 2012; Brooks and Waters, 2011; Koh, 2017), child migrants and schooling (Berg, 2015; Hanna, 2018) and education and migration in contexts of displacement (Arnot et al., 2009; Fiddian -Qasmiyeh, 2010, 2015; Dasstalaki and Leivaditi, 2018). All of this work speaks to the significance of education for structuring and effecting mobilities and socio-cultural differentiation of different kinds, globally. Some writing on educational mobilities explores the intersection of migration and education - education is seen as an increasingly important driver of international (and internal) migration, globally (King and Raghuram, 2013; Leung, 2013; Madge, Raghuram and Noxolo, 2015; Findlay et al. 2012; Waters, 2008). This research has tended to emphasise the agentic nature of educational mobilities - that they are enacted through choice, from a position of relative privilege and empowerment and that they tend to reproduce systems of social differentiation. Far less work on educational mobilities has discussed how they may be disempowering (for some people), or a function of state power and control. This is something we explore in this paper in relation to CBS. Some parallels may be found in work on 'birth tourism', as it has become known, which has been tentatively linked to ideas around an 'ideal' education for the child (Waters, 2008; what Wang, 2017, calls 'reproductive futurism'). Yet, education as a primary reason why women give birth over borders, and all the associated mobilities and complications that ensue afterwards, needs far more intellectual attention than it has been given to date. 


\section{Materialities and assemblages of mobilities: at the port/border}

Mobilities are, in various ways, material in nature, as the work of Adey (2008), in particular, has shown (Brooks and Waters, 2017). Mobilities necessitate an accompanying, supporting infrastructure, whether that includes roads, vehicles, traffic lights, pavements, canals, runways or air traffic control towers. In addition to their hard material infrastructure, ports are also 'affective space[s]' (Adey, 2008, p. X) and illustrate 'how...expressions of hope, fear, joy, sadness, and many others, as well as...mundane bodily motions...may not be as distanced from power and control as we expect'. In particular, we are interested in political boundaries as places where mobilities, materialities and power come together (Burrell, 2008). The border is the state's explicit attempt to control people, but it does not have total control, and it is these interstices (in state power) that are particularly intriguing and on display through CBS.

The notion of assemblage, as a 'mode of ordering heterogeneous entities so that they work together' (Muller, 2016, p.28), is one way of approaching the mechanisms of cross-boundary schooling. Assemblage thinking has developed from the ideas of Deleuze and Guattari (1987) articulated in A Thousand Plateaus, which gives roughly equal ontological status to all things (humans, animals and 'inert' materials). The border assemblage, more specifically, could be used to describe how new territories are produced (and reproduced) through the coming together of different entities. In cross-boundary schooling, the border, and the wider region within which children commute, could be described as 'produced' in different ways. The border itself is a collection of 'things' (buses, passes, booths, desks, stairs, papers, doors, turnstiles, chairs) and 'spaces' (corridors, walkways, passages, floor areas) within, through and against which people move or become immobile. 
The 'state assemblage', as discussed by Dittmer (2018), is a useful way of thinking about the materiality of the border and the configuration of human and non-human artefacts making up the border on a daily basis. The border is a manifestation of the power of the state, just as the state (and politics) are inherently material (Barry, 2013). It is important not just to think about the border in CBS in the abstract, but to ground it in notions of power and politics. In recent years, work by geographers interested in migration (such as Mountz, 2004; Mavroudi and Warren, 2013) have demonstrated the material basis for state power in controlling people's movements. CBS has emerged, we argue, directly out of state power - power to control mobility, fertility (through the one-child policy), citizenship and residency rights, identities and access to schooling.

\section{Rhythms, habits and movement across the boundary}

In this project, we are interested in exploring how educational mobilities intersect with state control. Control can be both large scale and systematic (as seen with population policies that constrain women's fertility) and more seemingly banal (such as control over the flows of children across a border, whilst the movement of their parents is restricted). At the same time, children themselves can attempt to reassert some measure of control over their own commute. In much of the literature, time spent at borders - crossing the border - and commuting between home and school more generally is depicted as 'lost time'. Chiu and Choi (2018, p. 5) describe 'hypermobile children and their carers' as 'train[ing] to become warriors fighting against time'. They go on to depict the strategies parents deploy to 'make up' for 'lost' time at the border. The time at the border, and the significance of the border itself, however, is not subject to examination in their work. Finn and Holton (2019) have looked specifically at the 
mobilities associated with commuting for education and have sought to challenge the idea that time spent commuting is time 'wasted', and instead (for their higher education students) offers a chance to catch up on reading, to plan, to keep in touch with friends, to find time for solitude and escapism and even to enable moments of social intimacy. Similarly, we look at rhythms and habits as a way of understanding the significance of time at/over the border for CBS children, proffering a counternarrative to the idea of 'lost' time and an absence of control.

The idea of rhythms is an arresting and potentially fruitful way of thinking about how bodies move across the border and, we would argue, provides a useful lens through which to explore in particular children's cross-boundary mobilities. Geographers interested in rhythms have drawn upon Lefebvre's notion of 'rhythmanalysis' (Edensor and Holloway, 2008; McCormack, 2002) to explore how lives 'and the spaces we dwell in and move through are composed of a multitude of different rhythms, temporalities, pacings and measures' (Edensor and Holloway, 2008, p. 483). Of especial interest to us in this paper is researchers' exploration of how rhythm and power intersect: 'how power attempts to order particular rhythms so they become habitual, embodied and thus difficult to knowingly contravene' (ibid., p. 483). Clearly, when it comes to a state border, a sense of rhythmic ordering is vital to ensure its smooth functioning - that people are able to cross in an orderly, ordered, controlled way. The fact that we are dealing with tens of thousands of young children makes this notion even more intriguing (can it work?). Conceivably, through their mobilities, children also make the space of the border, as implied through Lefebvre's (2004) rhythmanalysis, which connects space, the body and rhythm, and proffers that spaces are created through particular rhythms enacted by different bodies. Certainly, when it comes to children, CBS is habit and a routine, as evidenced by the 'natural' way in which children fall 
into line (see Figure 2; see also Ladru and Gustafson, this volume). However, we also wanted to explore in what ways rhythm can also be disrupted.

The rhythm of cross-boundary school is, in addition, habitualised, and resonates with Bourdieu's (1984) ideas around habitus (i.e. embodied socialisation) (Pimlott-Wilson, 2011) and other conceptualisations of habit. Middleton (2011), for example, has explored how decision-making around everyday mobilities in urban settings is habitualised - what she describes as being 'on autopilot'. Just as we want to alight on the border crossing, Middleton (2011, p. 2863) observes how researchers are paying increasing attention to 'what people do during trips, and a less rigorous separation of trips and stationary activities.'

In cross-boundary schooling, the power of the state 'seeks rhythmic conformity' (Edensor and Holloway, 2008, p. 501). It can be seen as a means of effective governing (of creating docile bodies). It is clear that children (and their parents) are controlled, to a large degree, by the rhythms and habits of cross-border schooling and their associated materialities - the consistency and sameness of the everyday, from waking up to getting dressed and boarding the bus, alighting and moving in lines, crossing the border, re-entering the bus, disembarking at school, as our data will show. In this paper we consider how the materiality of the border works to facilitate and disrupt 'rhythmic conformity'.

\section{Methods}

The project we discuss here was funded jointly by the University of Oxford and Utrecht University between 2017 and 2018. It is a qualitative study, aiming to uncover families' and 
others' past and/or present experiences of cross-boundary schooling. During 2018, we conducted fieldwork on CBS at the Hong Kong-Shenzhen border (see figure 1). There were three key stages to the fieldwork. The first stage, from February to March 2018, involved recruiting research participants to the project using friends, social media platforms, and news reports. Information about the research project was disseminated on the research assistant's WeChat [Chinese twitter] page. At this initial stage, seven families (fathers or mothers with children) were identified and contacted. Furthermore, a WeChat public platform/forum on 'cross-border kids' was uncovered, and the founder of the forum was contacted. In March 2018, we conducted the first round of interviews in Shenzhen, involving five mothers and three fathers (from the seven families). Some interviews were conducted in public places (canteens, restaurants, coffee shops or fast food outlets); two families invited us into their homes. The research assistant was able to accompany one family (LWM and $\mathrm{DD}^{6}$ ) on the journey from the port to their home (together with their children).

The second stage of research commenced around June 2018, including a second round of interviews, looking for new contacts, and conducting port observation. Four families agreed to be interviewed for the second time (our goal was always to interview a small number of families in greater depth, including repeat interviews where possible, rather than obtaining a 'large' sample). In addition, five new families were interviewed. The new contacts were largely introduced by the previous informants. Among the new contacts, four families had returned to Shenzhen for schooling and one family had decided to commence cross-boundary schooling after attending schools in Shenzhen for several years. We were as interested in talking to families that have stopped CBS, and their rationales for doing so, as those currently

\footnotetext{
${ }^{6}$ The initials we use are pseudonyms.
} 
engaged in CBS. In addition, our research assistant joined two WeChat groups (both for CBS parents; each group included around 400 members): one was founded by a social service organization (Shenzhen-Hong Kong family service); the other one was initiated by a CBS parent. The online groups proved very useful for aiding understanding of parents' ideas, concerns, and experiences.

The third stage of fieldwork began at the beginning of July 2018, and included port/border observation and interviews. The research team went to Shenzhen from Hong Kong through Luohu port station, and visited Luohu Cross-boundary Students Services Center (their Head office). We also conducted a focus group with teachers and one older CBS student who had crossed the border for 10 years. We continued to conduct port/border observations at Fu Tian port and Shenzhen Bay Port during the first week of July, three times a day: morning (6:30$8: 30)$, noon (12:00-14:00), and late in the afternoon (16:00-18:00), when the majority of CBS children go to Hong Kong or return to Shenzhen. The research assistant interviewed one government officer working at Shenzhen Customs, a grandfather (who picked up his grandson at the port), a high-school teenager (16 years-old) who had been engaged in CBS for around 10 years, two 6th-grade teenagers (12 years-old) who had been commuting for 6 years, and one staff member at a tutoring centre at Fu Tian Port. A second research assistant carried out a small number of interviews with Hong Kong-based teachers and teaching staff about their experiences of CBS. Most of the interviews were conducted in Chinese (Mandarin) and were translated by the research assistant during transcribing. The transcription was then double-checked by one of the researchers for accuracy. A smaller number of interviews (for example, with two older students and some school teachers) were conducted in English by the co-investigators. The positionality of the research team was varied. Two of the four were born in Hong Kong, with Hong Kong resident status, one was 
born in the PRC with Mainland hukou, and one has British citizenship. All the team, therefore, are differently 'positioned' vis-à-vis their experiences of education and politics between Hong Kong and the PRC. To summarise the data, our project has involved interviews and observations with 12 families in-depth, plus eight interviews and one focus group with teachers, four additional interviews with children and one interview with a government customs officer.

Figure 1: the Shenzhen - Hong Kong border (attached file)

\section{Discussion: Cross-Boundary Schooling}

'The material affordances of the space restrict capacities to make, disrupt, and transgress the physical environment and the intentions it embodies' (Adey, 2008, p. 439).

The Shenzhen-Hong Kong boundary is an internal border that functions, to all intents and purposes, like an international (securitised or 'hard') border with the infrastructure, machinery and technology that one would associate with the border between two nation states. In this paper, and based on our fieldwork, we want partly to explore the infrastructure that makes cross-boundary schooling possible, as a manifestation of state power and an example of the concept of a 'state assemblage'. 
As noted above, this paper is concerned with uncovering two particular aspects of crossboundary schooling between Shenzhen and Hong Kong: first, those materialities (props, artefacts, structures and barriers) that serve both to facilitate and impede and / or interrupt flow. And second, those relating to notions of habit and rhythm, which create ostensible 'flow' (in educational mobilities) over and through the border. We focus on uncovering places and moments of stasis (involving stopping, and pausing, waiting, looking, sitting, sleeping) amidst a mobility of bodies and continuous, orchestrated movement. We ask how it is that the impression of flow is achieved in such a constraining, restrictive space of the border, where children (who do not always submit to being directed) are involved. The empirical discussion of our findings moves as follows: we begin by focussing on infrastructure and material assemblages at the border. We then consider the extent to which notions of rhythm and habit might characterise how children and families apprehend the border on a daily basis. We look at the role of carers (especially 'nannies') in directing and facilitating CBS. And finally, we consider instances where individuals were seen not to conform to the structured materiality and rhythmic expectations of the border.

\section{Material assemblages: 'control' at the border}

The ports, marking the border between Shenzhen and Hong Kong, are very distinct places and a demonstration of state power. They bring together an orchestrated collection of material 'things' (barriers, booths, seating, gates, terminals, walls, technology such as scanners, firearms and batons), designed to control people and goods (to prevent unmitigated flow) (see 
figures $2-5^{7}$ ). At the same time, it is important that the border does, to a certain extent, allow a degree of flow, especially in a scenario where tens of thousands of children are attempting to cross over, in the space of an hour or so every morning and evening, to attend school. Any significant hold-up could invite 'chaos'. The fact that they are children - and not adults - adds an interesting and unexplored dimension to border crossings. As noted to us by a customs officer who works at the border, because CBS students are young (and cannot be controlled using 'normal' means) this causes a real headache for port officials. She observes:

'Those CBS kids, they commute every day, putting a lot of pressure on and challenges to the port: the customs and border patrols. Normal visitors also feel the pressure. Because there are so many little kids [mixed] within the visitors, their safety is a big concern. The [Shenzhen] government asked the port to solve the problem. At that time, the port didn't have the extra resources and staff to supervise the CBS kids. Moreover, kids are unlike normal adult visitors. Kids, you couldn't beat or scold them, right? So the port tried to solve the problem by arranging a special channel for the kids.' (Fieldwork interview with SX, government officer, Shenzhen customs, 2018).

Therefore, the port has found a material solution to the 'need to control' children (ostensibly for their own safety and comfort) and that was a 'special channel' (see Figure 2) - a demarcated and separate space.

Figure 2. Photo by researchers.

\footnotetext{
${ }^{7}$ Children's faces are blurred in photographs taken by the research team where they may be identifiable. We have not blurred the faces of children in photographs publicly available on newspaper websites.
} 
Cross-boundary students (CBS) require valid proof of identity or travel documents, from both the Mainland Chinese and Hong Kong authorities, to commute between Hong Kong and the Mainland via various boundary control points (BCPs). To ensure the safety and orderly transit of CBS, various ports in Shenzhen implement special channels for CBS during 'peak hours', and dedicated CBS waiting areas. In addition, meeting points, waiting areas and elevators are dedicated for CBS at particularly busy crossings. An 'on-board clearance' service for cross-boundary school buses is available at several boundary control points (see Figure 1 for details and also see Figure 5). In this scenario, CBS children do not need to get off and on the school bus for clearance. Designated e-Channels for CBS have also been installed in recent years, as shown in figures 3, 4 and 5.

Figure 3.

Figure 4.

Figure 5.

Photos source: https://www.immd.gov.hk/publications/a_report_2012/en/ch2/index.htm 
New procedures have made use of information technology and portable devices to enhance the immigration clearance process for CBS. Applications for the service have to be renewed every year [both for the e-channel and the On-board Clearance Service]. A recent photograph of the child is required on this application. This has reduced the amount of time immigration officers need to process every child - to as quick as only 6 seconds in some cases. Previously, children crossed the border with more conventional documents, usually with 5-year validity. Frequently, children did not look like the photo on their document, making the process of checking children's identity very time-consuming for officials.

The issue of child safety, however, is an important one and was raised by several of our interviewees. As one parent interviewee (SX) observed, in previous years (before the implementation of special channels) young children were forced to stand in line with 'regular' visitors at the border, often separated from their parents or carers. Parents were required to go to a different crossing point, as the following interview extract with YY illustrates:

'I am a HK resident, not permanent resident, so I hold HK resident ID. When I send my elder son to kindergarten, when we crossed the border, I have to go the "HK residents" counter, and my son needs to go the "HK permanent resident" counter. There are always many people to line up at the counter of "HK resident", there are fewer people at the counter of "HK permanent resident". At that time, he was only three-years old, and he went to the counter by himself. At the beginning, he could not do it. When the officer asked him about his name, he was afraid and unable to answer. 
Some officers were nice and kindly, will ask him, what's your name? where is your mum? Then let him go. Some officers were different and resolute, they asked, where are your parents? You are too young, and didn't allow him to pass the border by himself. Sometimes, the people behind him were very impatient, and would urge him to be quick, etc. When my elder son was very little, when he passed the border, there were always some incidents so that I usually argued with others' (Interview with YY, mother of CBS child).

This quotation indicates the impact that installing a 'specific channel' for CBS children, a space away from adult others trying to cross the border, has had for transforming the experience of boundary crossing. An older teenager, whom when much younger had tried CBS for a year (and 'just couldn't do it'), told us a similar story of being 'fearful' at the border ('It was pretty scary to cross the border alone. I felt pretty lonely and helpless'). He went on to say that he was 'jealous' of CBS children today, who have 'the facilities set up to help them'.

\section{Mundane materialities}

DD is originally from Hunan Province in the PRC; her husband LWM is from Taishan, Guangdong province. The couple has two children. Their elder son is 10 -years old, born in Shenzhen, and goes to school in Shenzhen. The younger daughter is 6-years old, born in Hong Kong, and has commuted there as a CBS pupil for 3 years. Our interview was conducted during a pause in the movement, on a bench at Futian metro station as children 
filed by. It describes the mundane materialities and very restrictive spatial arrangements associated with CBS, facilitating movement.

Interviewer: Are these [children] also [CBS pupils]?

DD: Yes, all primary school pupils. These all take the school bus back. You see? They all carry a yellow pouch.

Interviewer: What is in it?

DD: Documents, immigration documents. Their Exit-Entry Permit, Home (Mainland China) Return Permit, Hong Kong Re-entry Permit, and also the telephone of the 'Ah Yee' [nanny] company. And there is also the Closed Area Permit from Hong Kong. That is for Lok Ma Chau. That is a Frontier Closed Area. You are not allowed to just enter. For children from there, they need to apply for this document, the Closed Area Permit. I can show you later in the afternoon.

Younger children's documents will be collected either by the Ah Yee (or teachers) and be kept safe at school. For children who come late to school or leave early, parents/guardians have to remember to remind children to collect the documents from the school. Documents, of different kinds, are a profoundly important material aspect of CBS. They help create the state on a daily basis (Torpey, 2000). We were also able to meet the founder of a Wechat group for the parents of CBS pupils (he has a 7-year-old CBS child), with over 5,000 members. He discussed one of the most common topics raised on the forum - misplaced and lost documents. He said: 
'It's a big problem. That happens often. So we use the media platform to share this news. Our WeChat group is big, so we can help spread the news widely. If someone finds it, he/she can contact us immediately. I see this as contribution to protect the rights and benefits of CBS children and families.'

In addition to documents, parents also discussed the use of technology - specifically GPS watches, which have become increasingly popular amongst anxious adults. One interviewee, ZYY, has a son born in Hong Kong who has crossed the border since age 4 (he is now 11 years old). She told us:

'We use the watch every day. It is like a mobile phone. We can call. There is also GPS on it. I have an app on my mobile home. With that, I can see where he is. I know where he goes to after school. I can also call him.... You can get this in many places. A few hundreds, a thousand plus (around $£ 100$ ). You can get it from one of the malls here. He turns it off when he is at school.... Our school is rather strict. He has to put the watch in the school bag during class. After school, he can turn it on. Then my phone can track immediately his position, and I know that where has reached, when, when he crosses the border, and the like. Very clear.'

GPS watches are one example of how technological developments have transformed the experience of CBS - consequently parents are able to monitor their children's mobility over the border, providing them with reassurance but also some practical assistance (knowing when to leave home to collect their child from the bus). There is no doubt that parents feel empowered by the use of GPS watches. 
Daily rhythms of CBS: routine and habit

The term 'everyday' appears frequently in our interview transcripts, suggesting the extent to which CBS is routine, habit and part of a quotidian rhythm. This is an important part of state power: as Edensor and Holloway (2008) have argued, 'power seeks rhythmic conformity...' (p. 501), and this is especially true of daily border crossings. AL, a sixth-grade (12-year-old) pupil who had been commuting to school for six years said, matter-of-factly, 'we have got used to it'; and ZY, whose 6-year-old has commuted for three years similarly said 'Yes, it [school in Hong Kong] is far away, but if you get used to it, it is OK.' DD, who also has a 6year old who has commuted for three years, told us: 'we have been like this for several years. We get used to it. At the beginning I was afraid of several difficulties - after all, the kids are so small. But now we have adapted to it. Just follow the nannies!' (see. Figure 6). The following two quotations make the routinised and rhythmic nature of CBS quite explicit:

YQ: I and my mother-in-law, we got up around 5.30am and 5.40am every day, making all the preparations. Usually my mother-in-law prepared breakfast. I helped my son get dressed when he still had his eyes closed, then dragged him to the washroom, brushing teeth etc. Sometimes he brushed teeth when peeing. Then he ate breakfast while my mother-in-law helped him wearing shoes and socks. I even bought an electric motorcar to save time. It usually took $1-2$ minutes by electric motorcar from my home to the school assembly point. If I walk with him, it usually took $3-5$ minutes. 
LXM: She [daughter] gets up around 6am in the morning. I get up around 5.40am because I need to prepare breakfast. Then we set off around 6.20am. The cross-border bus will arrive around $6.30-6.35 \mathrm{am}$, just downstairs, she takes the bus, crosses the border then takes buses in Hong Kong to school. In the afternoon, I will go downstairs, pick her up around 5.30 - 5.40pm...Everyday she leaves home around 6.30am, crosses the border around 7.10am and gets to school around 8.15am

The quotations describe precise timings - this was a very common feature of our interview transcripts. CBS takes place according to a strict and necessary schedule - several interviewees described the fear of 'missing the bus', and the consequent 'nightmare' of getting their child to school, over the border, without the supporting infrastructure that the cross-boundary bus affords.

Figure 6. Photo by researchers. The nannies are in pink.

There is still, however, a degree of unpredictability (leading to stress) about the whole process - the individuality of border guards, buses not turning up on time, papers being lost (see above), and so on. For example, although DD claims she is "used to it", when asked how long the journey takes, she replied:

'It depends. Our home is not near the subway and we have to take a bus three stops.

We also need to factor in the time we wait for buses, which is unpredictable.

Sometimes it comes immediately, sometimes we have to wait for a while. In addition, 
it usually takes four minutes to wait for the subway. So it usually takes 40 minutes from home to the port, sometimes it takes 30 minutes, if it is fast.'

The uncertainty in her account - it depends, sometimes, usually, unpredictable - illustrates that even when CBS becomes habit and routine, families need to 'factor in' the possibility of divergence. Several families indicated that the stress of CBS came from the occasions when things did not go to plan - did not work as anticipated - such as when a bus was missed.

As indicated in a quotation above, nannies (or Ah Yee) have a very important role to play in the functioning of CBS. Nannies are often employed by the bus companies. They accompany the children across the border, they keep them in line, together. During our time spent at the border, we saw dozens of nannies wearing distinctive coloured tops that the children can recognise quickly, herding young children up and down stairways, through barriers and doorways and on and off buses. In figures 6 and 7 the nannies in pink tops can be clearly seen. They flank the children with their torsos and arms, creating physical mini-barriers with their bodies.

Figure 7. Photo taken by researchers.

Parents also gave us an interesting insight into the role played by nannies. LSC has two daughters. The younger one, who was born in Hong Kong in 2010, engaged in cross- 
boundary schooling for four years (2013 to 2017) and returned to Shenzhen for schooling in September 2017. She said:

'There are one to two Ah Yee ['nannies'] on each bus. They train the kids to be very obedient. They follow rules. They must sit there, remain sitting, put on the safety belt. Yes, my daughter behaves well. Ah Yee will also give her something as a reward. This one is quite good. But there are some really fierce ones. Actually, I can understand, especially when the kids are naughty, and there are so many of them. These Ah Yee have to mind so many kids. But still, of course, if we, as parents, see these Ah Yee treat the children this way, we would be very sad. But, there is no choice. Otherwise, they cannot keep them under control. They need to keep them under control.'

According to parents, then, a key role of the Ah Yee is to keep children under control. From our observations, we would add, the Ah Yee's role is to control children's mobilities - to keep them moving when they are supposed to move, and keep them still (in line, in their seat) when they are expected to remain still. Although most parents rely on the "nanny infrastructure' to get their children to school in Hong Kong, occasionally parents are able to travel with their child. SY was very critical of the way in which Ah Yees treat young children, telling us:

'We saw the kids going to school on a school bus. The Ah Yee seemed very fierce. When the kids got off the bus, being a bit naughty, these Ah Yee would pull them down with force, very fierce. Once I saw a child loss his balance, fell on his face and 
his mouth was all swollen. He bled a lot. The Ah Yee would surely say it was the child's fault.'

Without a doubt, children are disciplined in border crossing. They are taught the rules and expected to obey them. At a Sacred Heart of Mary Catholic Primary School's CBS parents' meeting, it was emphasized that, when crossing the border, children must obey the following rules: always follow the nanny; do not leave the group and keep quiet; and do not cause nuisance to others. Other school bus rules that we came across on posters and leaflets at the border included: 1. Don't play with the emergency exit door; 2. Don't talk to the driver or shout during the journey; 3. Don't put the head, hand, or any part of the body out of the window; 4. Don't get on or off a school bus/nanny van while it's still moving; 5. Don't eat, drink or play during the journey; 6. Must remain seated all the way; 7. Must board and alight from a school bus/nanny van in an orderly manner; and 8. Must follow instructions of the driver and escort. These rules are accompanied by child-friendly graphics depicting good behaviour (produced by the Transport Department) (Figure 8).

Figure 8. Photograph authors' own.

Discipline and routine have an absolutely crucial role in engendering the 'rhythmic conformity' that the state demands from potentially 'unruly' (and ostensibly 'vulnerable') children engaged in CBS and nannies are important actors in this state assemblage. 


\section{$\underline{\text { Example of counter-rhythms and short-cuts }}$}

Despite the highly routinised and controlled nature of the Shenzhen-Hong Kong border, we sought instances of 'exception'; cases, perhaps, of where alternative rhythms were apparent or where short-cuts (going 'off piste') were taken. One example was proffered by DD (a CBS mother), who is originally from Hunan Province in the PRC and has two children. The younger daughter, who is 6-years old, was born in Hong Kong, and had engaged in crossboundary schooling for three years at the time of the interview. DD told us:

'We [parents] are expected to bring our children to the third floor, gate number nine. The Channels for cross-boundary students are on the right side. All kids, as young as kindergarten pupils, cross the border there. But we are lazy. Since Ah Yee [the school bus nanny] comes also at that time, we let our daughter go with the Ah Yee.

Generally, the schools have rules as to where we need to bring the kids to. But since we saw that the Ah Yee also always comes by that time, we let her go up with her.... On the way back, we are also supposed to pick up our children at gate number nine. But we are sometimes too lazy, we sometimes pick my daughter up [over the barrier] already when she passes by the ticket-recharge area here. Because one needs to go around and about to gate nine. So we need to go in there and come back out again. That would take maybe seven to eight minutes. Some children have to catch their extra-curricular activities after school. So in a hurry, they will be picked up like here.' 
It is not just parents who are looking for shortcuts and ways of 'speeding up' the process, making their hectic lives a little easier. Children, also, are engaged in activities that enrich the experience, often related to countering boredom or fatigue. During our observations at the border, it was particularly interesting to note instances of where children were not, especially, conforming or 'playing along'. Edensor and Holloway (2008) discuss Lefebvre's notion of 'appropriated' time, where 'time no longer counts' (2004, p. 76) for individuals because they are 'absorbed' in an activity so that time passes unnoticed (such as in day dreaming, creative play or sleeping). These moments 'break up the mechanically repetitive rhythms of institutionalised time' (Edensor and Holloway, 2008, p. 486). In figures 9 and 10, we see children passing the time in this way: playing games on mobile phones (waiting for their escort), sitting on the floor in undesignated areas (re-appropriating space) and chatting and swinging their legs around as they do so. These are small acts, but matter for children's sense of self; for reclaiming parts of their day from the monotony, conformity and exhaustion that characterises CBS for most of the families we talked to.

Figure 9. Photo by researchers.

Figure 10. Photo by researchers. 
There is also the controversial issue of smuggling, in direct contravention of 'state control': adults using children to carry illicit goods across the border ${ }^{8}$. LSC, whose younger daughter undertook CBS for four years, stressed in her interview how 'easy' this process was as 'port supervision' was limited. Children can travel, as it were, 'under the radar' and so are perfect for exploitation by unscrupulous adults. Customs officials do not habitually check CBS pupils' bags (to keep the process 'flowing') and so children become targets for smugglers. News reports have suggested that children get 'paid' with fast food or other 'treats'. Such illegal smuggling is purportedly common place.

\section{Conclusions}

Tens of thousands of young people, aged from three to eighteen, cross the border between Shenzhen and Hong Kong on a daily basis, from the People's Republic of China and back, in order to attend school. They are part of a large cohort of children born under the one-child policy implemented (and now disbanded) by the Chinese government in an attempt to control fertility and the population as a whole. Widely described as an extremely successful policy, families from the Mainland nevertheless were able to bypass these draconian measures by crossing the border into Hong Kong to give birth (until this, also, was outlawed by the Hong Kong government in 2014). These children, often born in Hong Kong to Mainland resident parents, have different 'status' to the rest of their household. Although able to live in the PRC, they are unable to access health care or, crucially, (until 2017) state schooling. At the same time - and one of the many aspects that makes these CBS children and their

\footnotetext{
${ }^{8}$ Common items being brought across the border are mobile phones (expensive, high-end ones), external hard drives, cosmetics and other body-care items like lotions, and health products. They are sold to make money. Even though you can get practically any items in China now, there is a concern about counterfeit goods and differences in the quality of products in Hong Kong vis-à-vis in mainland China. Hence, a market for these things.
} 
circumstances so interesting - parents articulate a preference for all things Hong Kong (the quality of schooling, the language environment, the 'culture' and political milieu and also the possibilities for their child's future global mobility). Their decision making is discussed in terms of 'choice' and personal agency. Despite the fascinating situation surrounding CBS, only a handful of academic studies have explored it in any depth (Chan and Ngan, 2018; Chee, 2017; Chiu and Choi, 2018; Li, 2016).

In this paper, we have chosen to focus on the 'state assemblage' represented by the Shenzhen-Hong Kong border. CBS is a manifestation of the power of the state - to control people's mobilities, their birth choices, schooling, future mobilities and so on. There are far bigger issues at state than the ostensibly simple act of children crossing an 'internal' boundary in order to attend school; CBS represents a fascinating lens for addressing these bigger issues. In particular, we have looked at the materialities (the artefacts, infrastructures and actively constructed spaces) that direct and control cross-boundary mobilities and flows of children for schooling. Children appear, ostensibly, obedient; rarely moving 'out of line' or 'out of place', nearly always found in the special spaces allocated to them. We have sought to uncover the ways in which such flows are directed and controlled, as well as highlighting some interesting examples of where children do not 'flow' across the border - where they stop, sit, play, chat, engage with technology or perhaps sleep. Educational flows are punctuated by non-flows, counterflows or frictions.

It is important to uncover these processes for the contribution they can make to a number of different literatures and debates. First, to the grounding and 'materialising' of educational mobilities with detailed empirical examples (Brooks and Waters, 2017). Second, to the 
constitution and effects of state assemblages at 'the border' - in this case at an internal border that functions like an international border. Third, our paper makes a contribution to work examining experiences at political borders (and the particularly neglected quotidian experiences of children and young people). The situation between Hong Kong and Mainland China is dynamic and volatile, and CBS children are directly involved in the making of the border between them (socially, culturally and materially) on a daily basis.

\section{Acknowledgements}

The authors would like to thank Yun Yun Qin for her exceptional work as a research assistant on this project. The University of Oxford (Fell Fund) and Utrecht University generously funded this project. Thank you, also, to three anonymous referees for their insightful comments on this paper.

\section{References}

Adey, P. (2008). Airports, mobility and the calculative architecture of affective control. Geoforum, 39, 1, 438-451.

Anagnost, A. (1995). A surfeit of bodies: Population and the rationality of the state in postMao China. Conceiving the new world order: The global politics of reproduction, 22-41.

Barry, A. (2013). Material politics: Disputes along the pipeline. John Wiley \& Sons. 
Beech, S. E. (2018). Adapting to change in the higher education system: international student mobility as a migration industry. Journal of Ethnic and Migration Studies, 44, 4, 610-625.

Berg, M. L. (2015). 'La Lenin is my passport': schooling, mobility and belonging in socialist Cuba and its diaspora. Identities, 22, 3, 303-317.

Brooks R, Waters J (2011) Student Mobilities, Migration and the Internationalization of Higher Education, Palgrave MacMillan

Brooks, R., \& Waters, J. (2017). Materialities and mobilities in education. Routledge.

Brooks R (2018). Higher education mobilities: a cross-national European comparison, Geoforum 93, 87-96

Burrell, K. (2008). Materialising the border: Spaces of mobility and material culture in migration from post - socialist Poland. Mobilities, 3(3), 353-373.

Chan, A. K., \& Ngan, L. L. (2018). Investigating the differential mobility experiences of Chinese cross-border students. Mobilities, 13, 1, 142-156. 
Chee, W. C. (2017). Trapped in the current of mobilities: China-Hong Kong cross-border families. Mobilities, 12, 2, 199-212.

China Daily (Hong Kong) (2017):

https://www.chinadailyhk.com/articles/251/105/27/1504282214542.html accessed 11/07/19

Chiu, T. Y., \& Choi, S. Y. (2018). Frequent border-crossing children and cultural membership. Population, Space and Place, e2153.

Daskalaki, I. and N. Leivaditi Education and Hospitality in Liminal Locations for Unaccompanied Refugee Youths in Lesvos Migration and Society 1, 1: 51 - 65.

Deleuze, G., \& Guattari, F. (1987). A thousand plateaus. Minneapolis: University of Minnesota Press

Dewsbury, J. D., \& Bissell, D. (2015). Habit geographies: The perilous zones in the life of the individual. Cultural geographies 22, 1: $21-28$.

Dittmer, J. (2018). The state, all at sea: Interoperability and the Global Network of Navies. Environment and Planning C: Politics and Space. https://doi.org/10.1177/2399654418812469 
Edensor, T., \& Holloway, J. (2008). Rhythmanalysing the coach tour: the Ring of Kerry, Ireland. Transactions of the Institute of British Geographers, 33, 4, 483-501.

Fiddian-Qasmiyeh, E. (2010) 'Education, Migration and Internationalism: Situating Muslim Middle Eastern and North African students in Cuba,' The Journal of North African Studies, 15, 2: 137-155.

Fiddian-Qasmiyeh, E. (2015) South-South Educational Migration, Humanitarianism and Development: Views from Cuba, North Africa and the Middle East, Oxford: Routledge

Findlay, A. M., King, R., Smith, F. M., Geddes, A., \& Skeldon, R. (2012). World class? An investigation of globalisation, difference and international student mobility. Transactions of the Institute of British Geographers, 37, 1, 118-131.

Finn, K. (2017). Multiple, relational and emotional mobilities: Understanding student mobilities in higher education as more than 'staying local' and 'going away'. British Educational Research Journal, 43, 4, 743-758.

Finn, K. and M. Holton (2019) Everyday mobile belonging: theorising higher education student mobilities London: Bloomsbury 
Hanna, H. (2018) Crossing the border from 'migrant' to 'expert': exploring migrant learners' perspectives on inclusion in a primary school in England Children's Geographies DOI: $10.1080 / 14733285.2018 .1548693$

Holton, M., \& Finn, K. (2018). Being-in-motion: The everyday (gendered and classed) embodied mobilities for UK university students who commute. Mobilities, 13, 3, 426-440.

King, R., \& Raghuram, P. (2013). International student migration: Mapping the field and new research agendas. Population, Space and Place, 19, 2, 127-137.

Koh, S. Y. (2017). Race, Education, and Citizenship: Mobile Malaysians, British Colonial Legacies, and a Culture of Migration. Springer.

Lefebvre, H. (2004). Rhythmanalysis: Space, time and everyday life. A\&C Black.

Leung, M. W. (2013). 'Read ten thousand books, walk ten thousand miles': geographical mobility and capital accumulation among Chinese scholars. Transactions of the Institute of British Geographers, 38, 2, 311-324.

Li, X. (2016). Seeking identity: the transborder lives of mainland Chinese families with children born in Hong Kong. Global Networks, 16, 4, 437-452. 
Madge, C., Raghuram, P., \& Noxolo, P. (2015). Conceptualizing international education: From international student to international study. Progress in Human Geography, 39, 6, 681701.

Mavroudi, E., \& Warren, A. (2013). Highly skilled migration and the negotiation of immigration policy: Non-EEA postgraduate students and academic staff at English universities. Geoforum, 44, 261-270.

Middleton, J. (2011). Walking in the city: The geographies of everyday pedestrian practices. Geography Compass, 5(2), 90-105.

Mountz, A. (2004). Embodying the nation-state: Canada's response to human smuggling. Political geography, 23, 3, 323-345.

Newendorp, N. D. (2008). Uneasy reunions: Immigration, citizenship, and family life in post1997 Hong Kong. Stanford University Press.

Ong, A. (1999). Flexible citizenship: The cultural logics of transnationality. Duke University Press.

Patiniotis, J., \& Holdsworth, C. (2005). 'Seize that chance!' Leaving home and transitions to higher education. Journal of Youth Studies, 8, 1, 81-95. 
Pimlott-Wilson, H. (2011). The role of familial habitus in shaping children's views of their future employment. Children's Geographies, 9, 1, 111-118.

Jones, P., \& Evans, J. (2012). The spatial transcript: analysing mobilities through qualitative GIS. Area, 44, 1, 92-99.

Torpey, J. (2000) The Invention of the Passport Cambridge: Cambridge University Press

Wang, S. H. (2017). Fetal citizens? Birthright citizenship, reproductive futurism, and the "panic" over Chinese birth tourism in southern California. Environment and Planning D: Society and Space, 35(2), 263-280.

Waters, J. L. (2006). Geographies of cultural capital: education, international migration and family strategies between Hong Kong and Canada. Transactions of the Institute of British Geographers, 31, 2, 179-192.

Waters, J. L. (2008). Education, migration, and cultural capital in the Chinese diaspora. Cambria Press.

Waters, J. (2015). Educational imperatives and the compulsion for credentials: family migration and children's education in East Asia. Children's Geographies, 13, 3, 280-293. 
Waters, J. and Leung, M. (2018) Key-Note Presentation by Johanna Waters at Geographies of Education II Conference, Loughborough University.

Waters, J. and R. Brooks (forthcoming) Student Mobilities and Migration Palgrave Macmillan.

Xu, C. L. (2018). Transborder habitus in a within-country mobility context: A Bourdieusian analysis of mainland Chinese students in Hong Kong. The Sociological Review, 66, 6, 11281144.

Figure 1 is attached as a PDF.

Figure 2: 


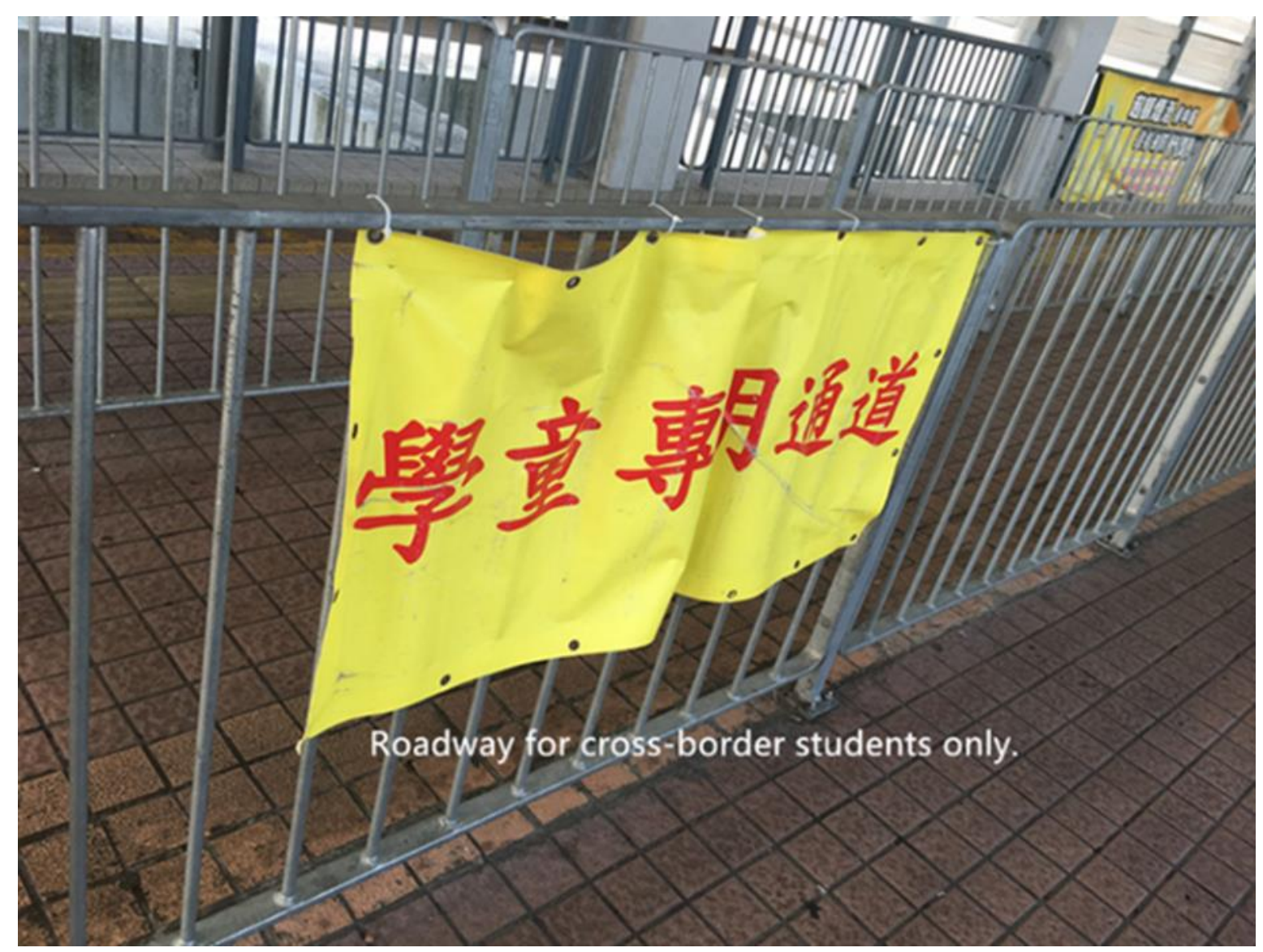

Figure 3: 


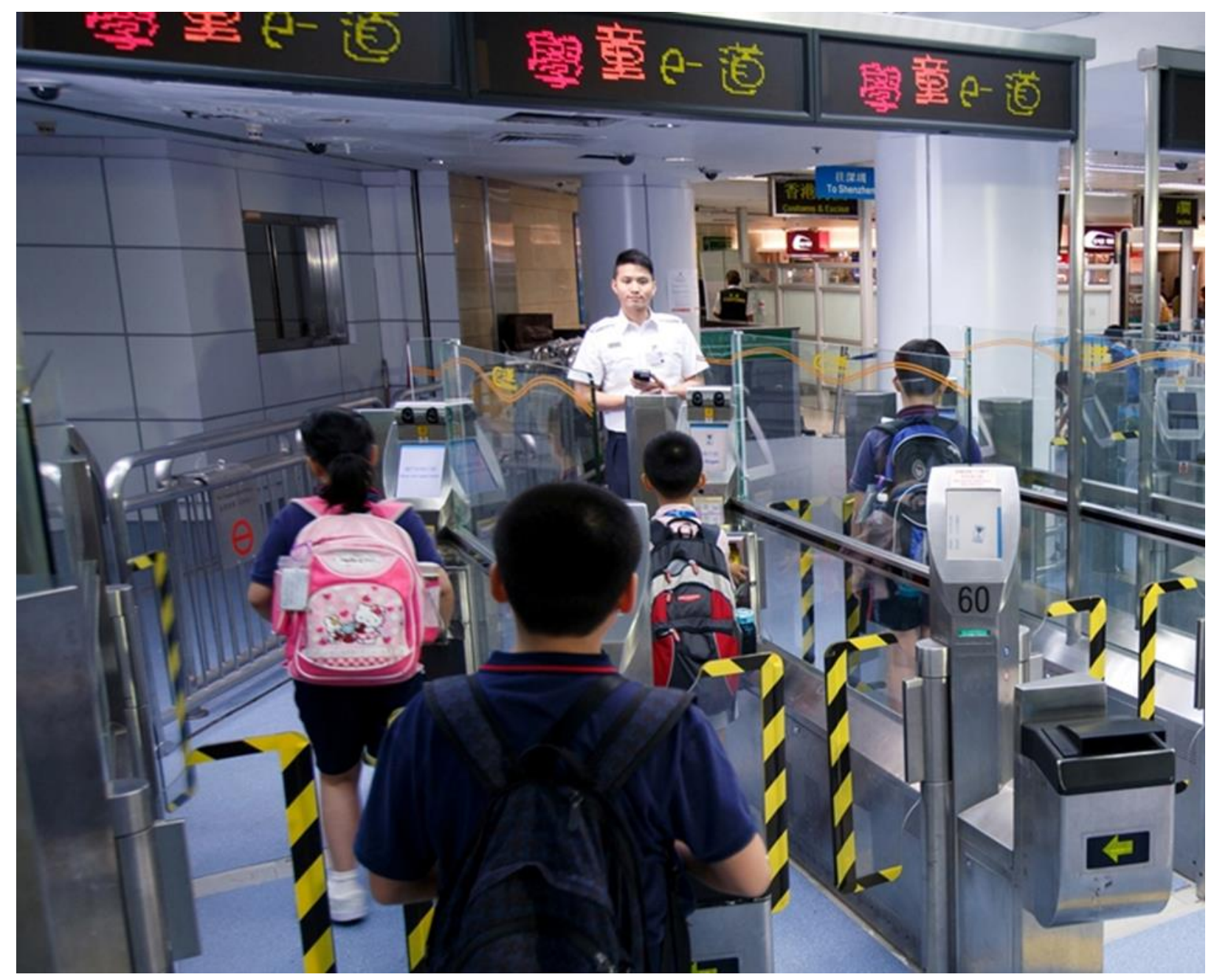

Figure 4: 


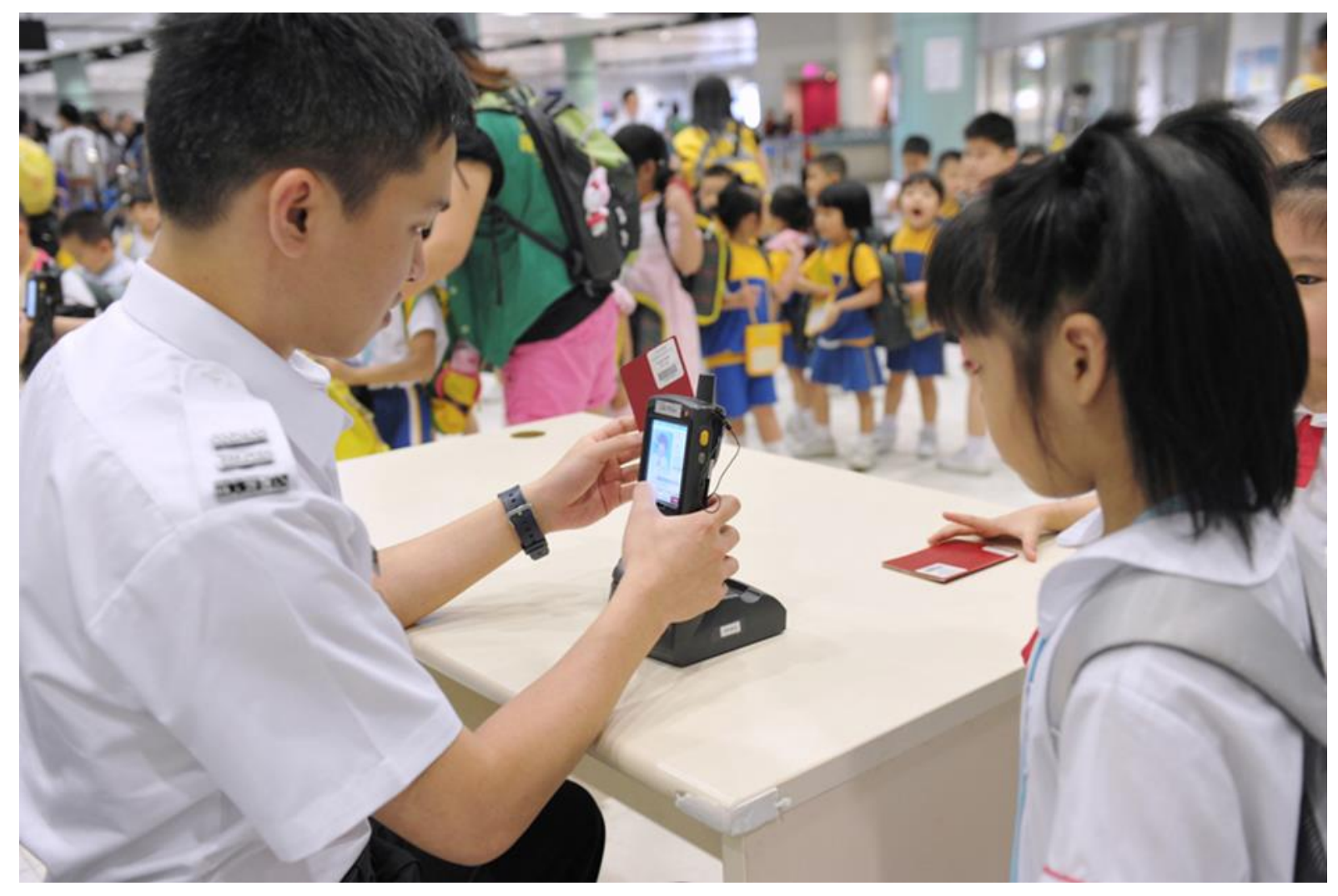

Figure 5:

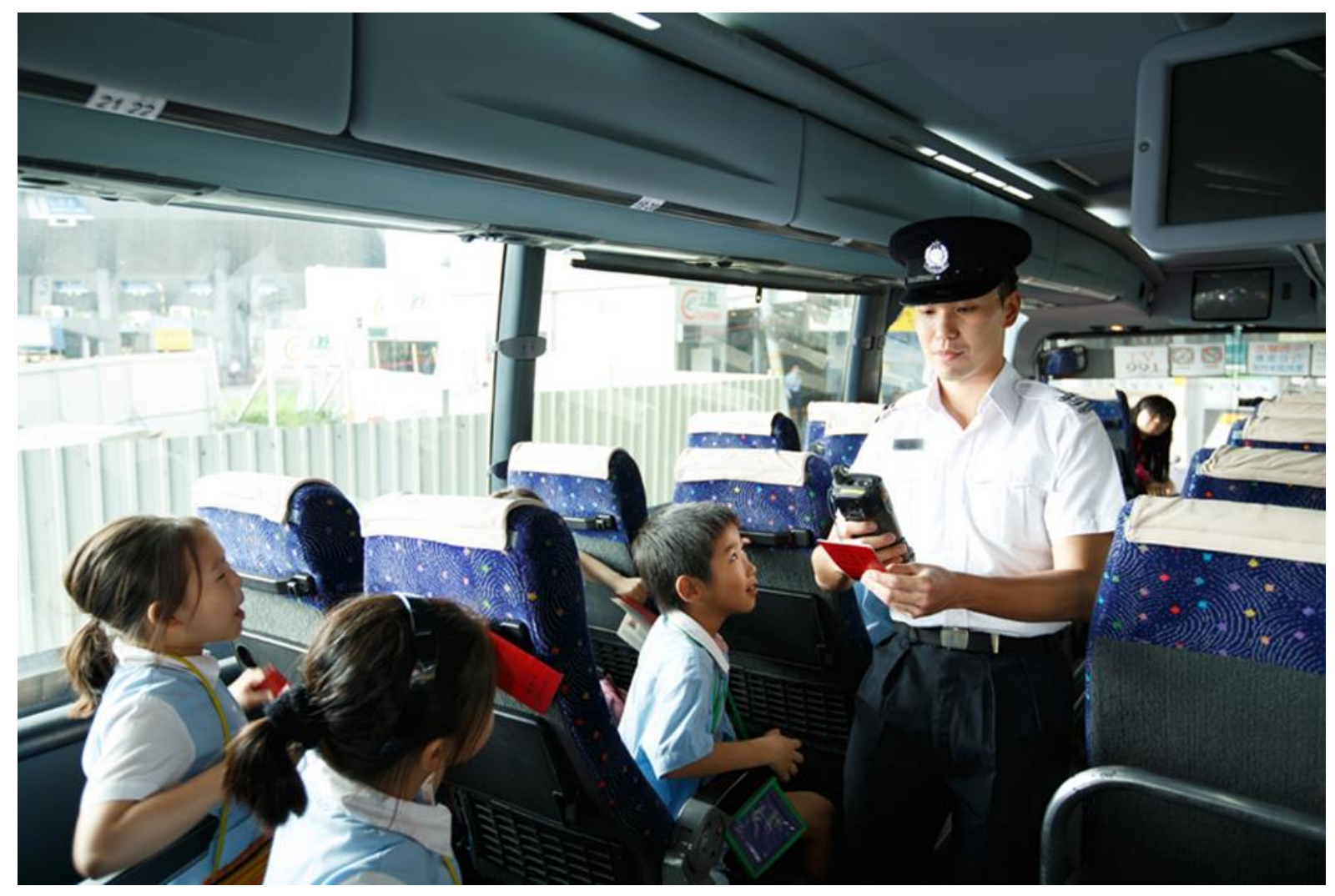


Figure 6:

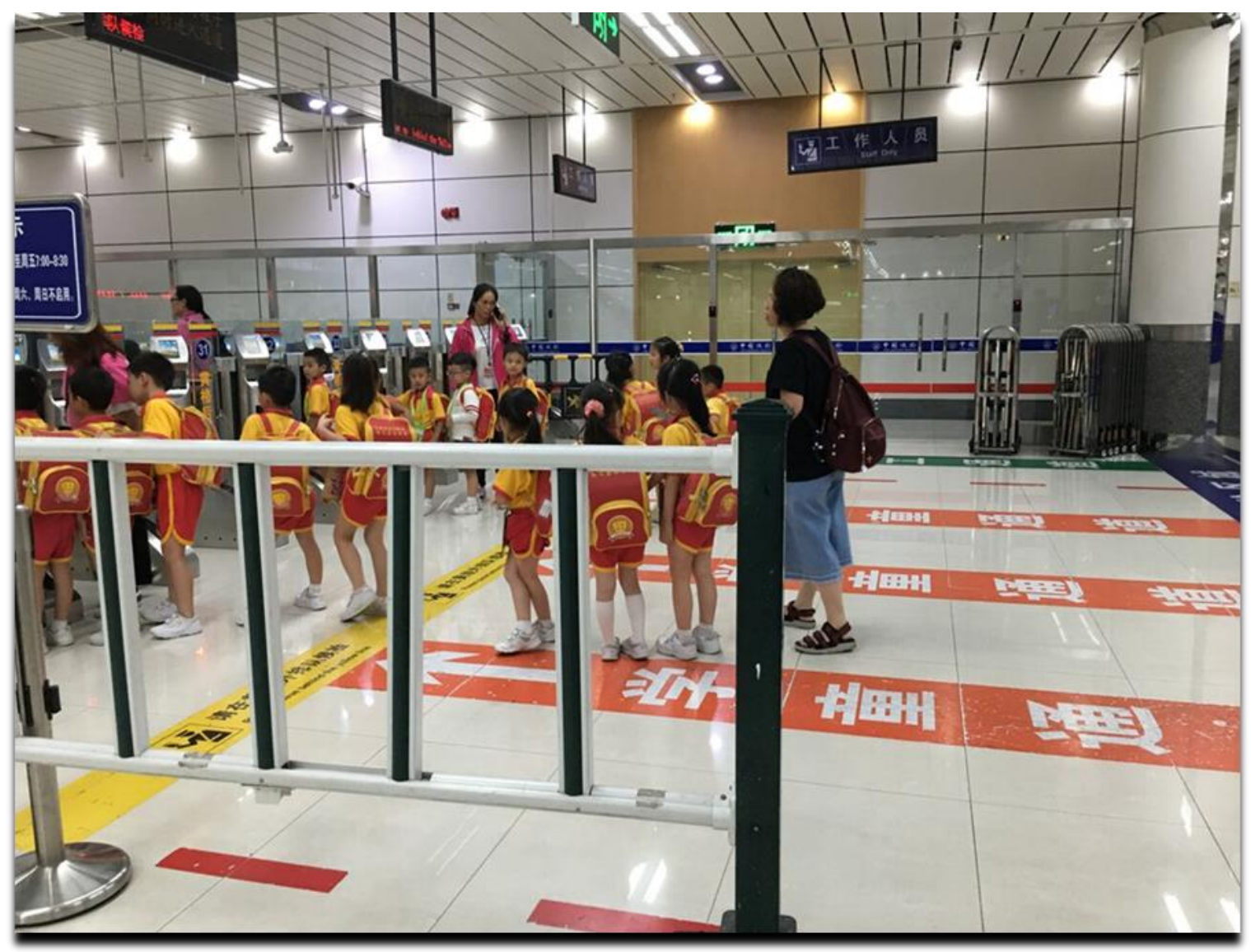

Figure 7: 


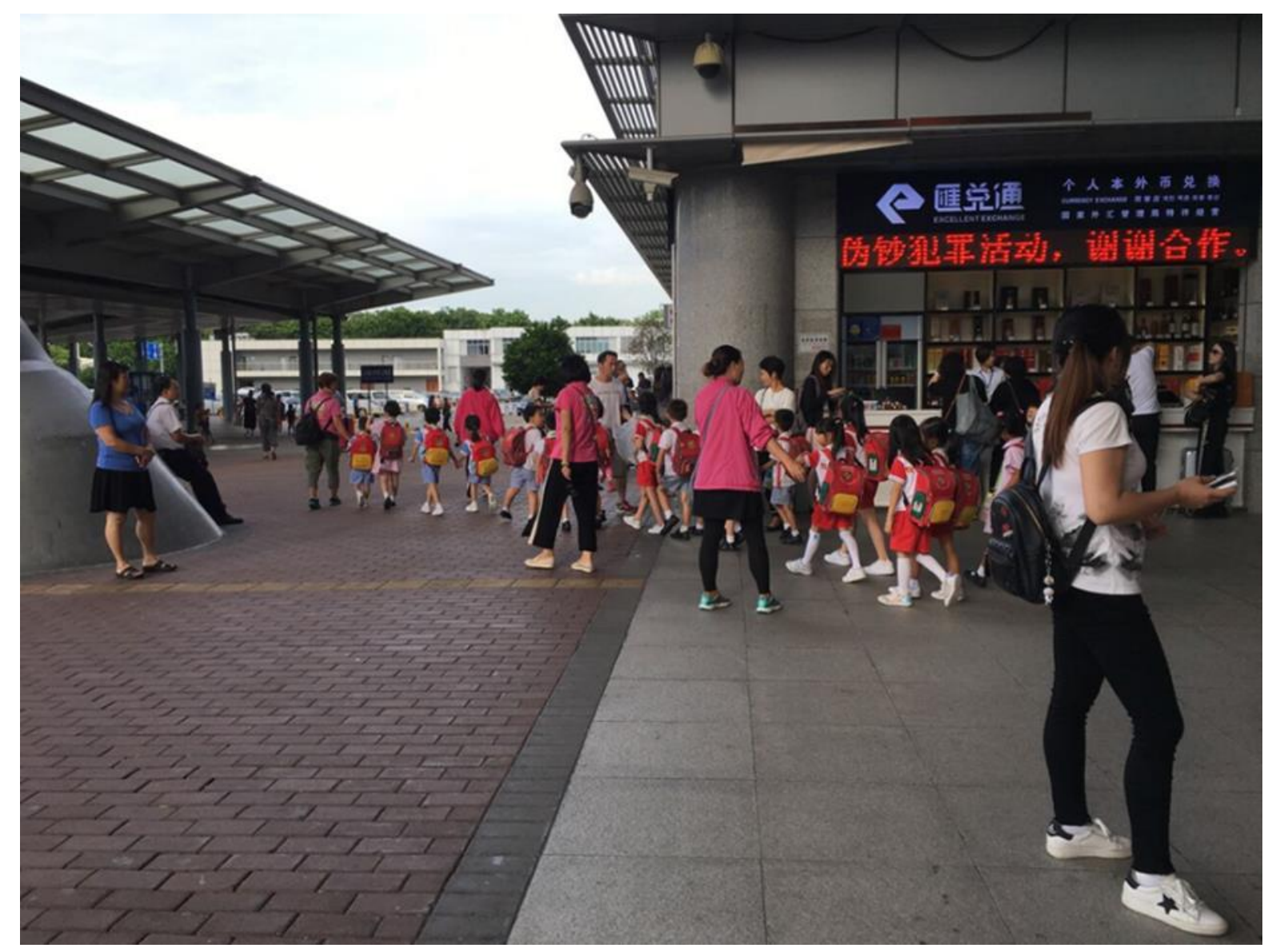

Figure 8: 


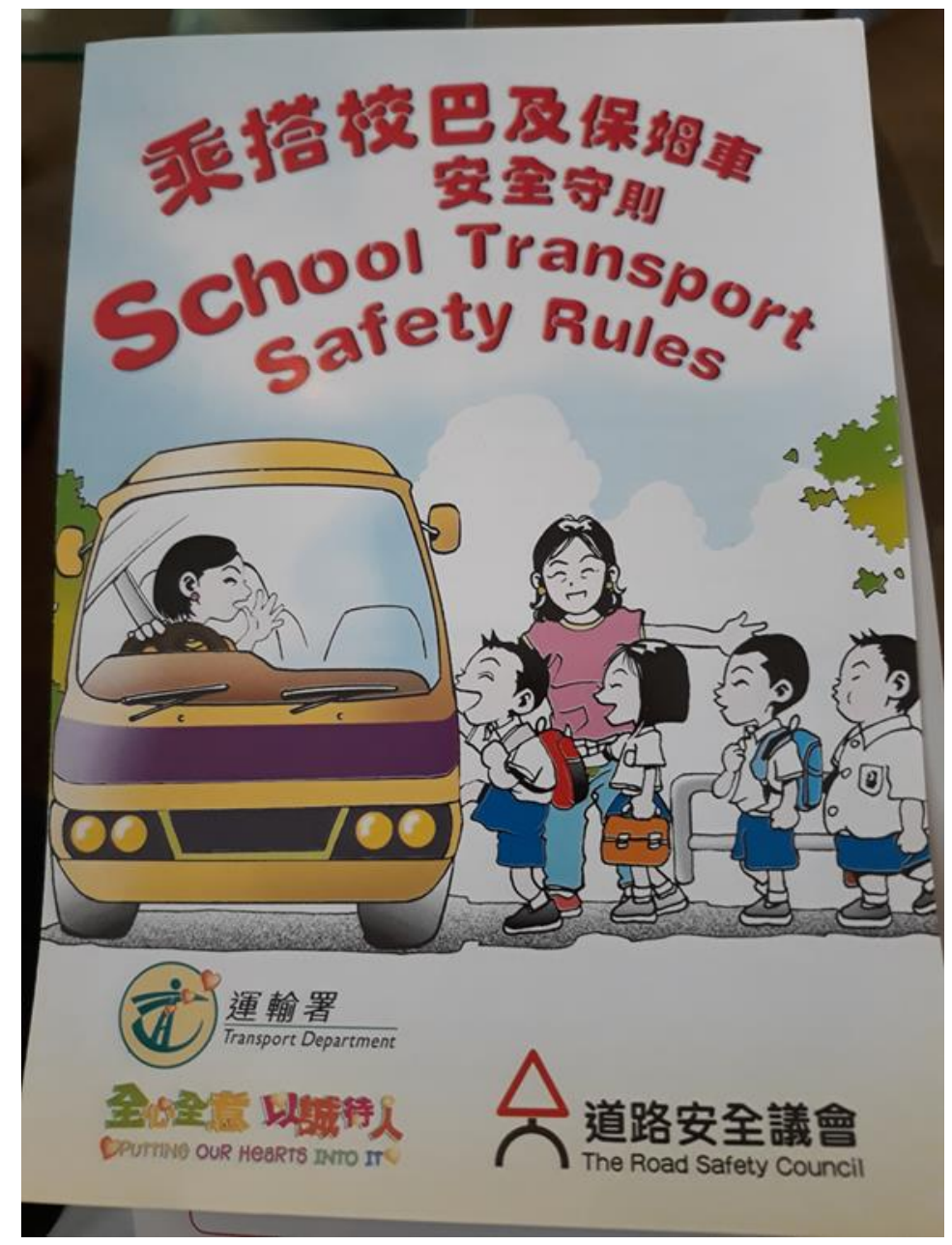

Figure 9: 


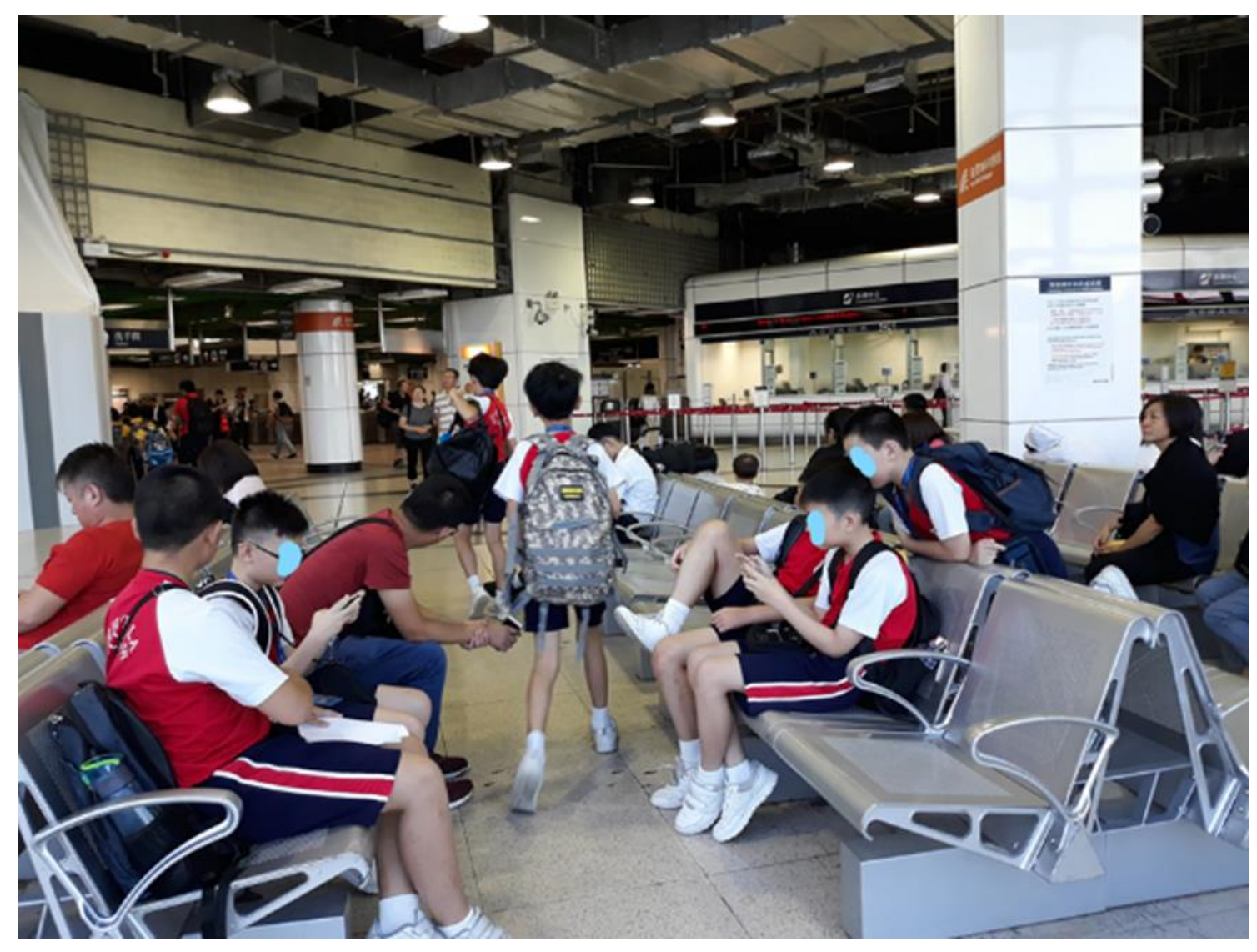

Figure 10: 


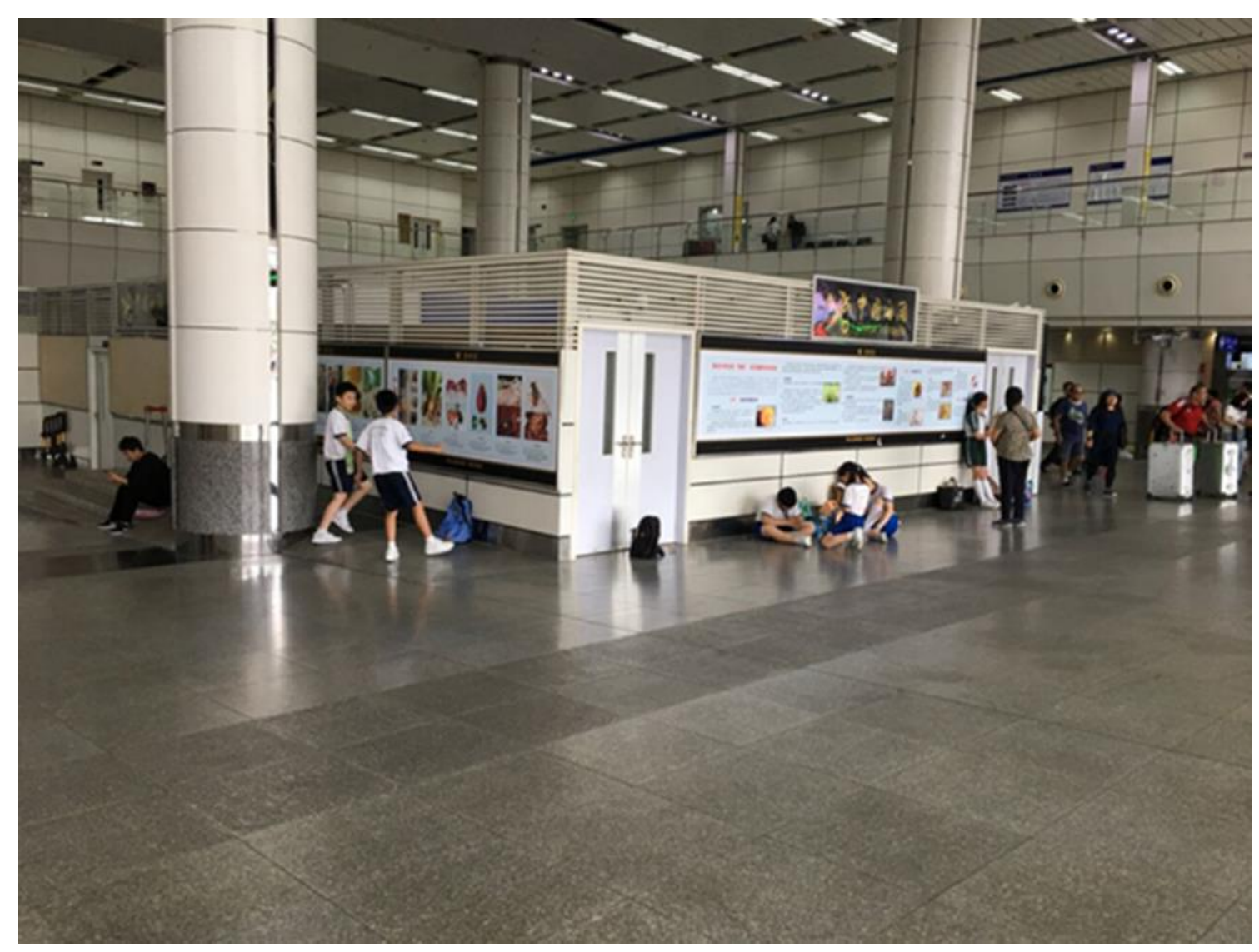

